\title{
PEMANFAATAN TEKNOLOGI INTERNET OF THINGS PADA ALARM SEPEDA MOTOR MENGGUNAKAN NodeMcu LoLiN V3 DAN MEDIA TELEGRAM
}

\author{
Rizky Hermawan', Abdurrohman² \\ Jurusan Teknik Informatika, Fakultas Teknik, Universitas Sangga Buana YPKP \\ ${ }^{1}$ rhermawan56@gmail.com
}

\begin{abstract}
ABSTRAK
Internet of Things (IoT) merupakan sebuah konsep untuk mengakses sebuah alat melalui jaringan internet. IoT menjadi sebuah konsep yang membuat praktis yang saat ini banyak dikembangkan dalam berbagai bidang. Dalam pengembangan IoT kami membuat alarm sepeda motor dengan menggunakan konsep IoT dengan tujuan untuk mencegah terjadinya pencurian dan perampasan kendaraan sepeda motor. Penelitian ini menggunakan model prototipe dimana terdapat empat langkah dalam menggunakan model ini, diantaranya tahap pengumpulan data, tahap desain cepat, membangun prototipe, dan tahap uji coba serta evaluasi. Komponen-komponen yang digunakan pada penelitian ini menggunakan NodeMcu LoLin V3 sebagai pengolah data yang masuk dan keluar dan menggunakan media Telegram bot sebagai sarana komukasi antar perangkat, dan komponen lain yang digunakan adalah sensor getar untuk mendeteksi getaran apabila sistem alarm dalam keadaan hidup, sensor tegangan untuk mengatur tegangan yang masuk, relay sebagai saklar otomatis untuk menghidupkan motor dan buzzer. Semua komponen di rangkai sedemikian rupa sehingga menghasilkan sebuah prototipe alarm kendaraan sepeda motor yang dapat diberi intruksi oleh aplikasi Telegram. Dari tahap pengujian seluruh komponen mendapatkan hasil kinerja yang baik dan dapat berkomunikasi dengan telegram bot yang sudah dibuat. NodeMcu LoLiN V3 dapat terhubung dengan koneksi internet yang dibagikan melalui tethering and portable hotspot dari sebuah ponsel dan dapat memberikan respon dengan mengirimkan pesan melalui telegram, sensor tegangan dapat mengatur arus listrik yang masuk apabila arus lebih dari $1.5 \mathrm{~V}$ maka respon yang dikirim ke telegram adalah terjadi tindakan terhadap kendaraan sepeda motor, sensor getar dapat berfungsi apabila terjadi getaran, serta komponen yang lain dapat berfungsi dengan baik.
\end{abstract}

Kata Kunci: Internet of Things, NodeMcu LoLiN V3, Model Prototipe, Multisensor, Telegram Bot

\section{PENDAHULUAN}

Kendaraan bermotor pada era ini telah banyak dimiliki oleh masyarakat diseluruh dunia baik itu kendaraan bermotor roda empat maupun roda dua. Di Indonesia kendaraan bermotor roda dua menjadi pilihan bagi masyarakat, pada tahun 2018 kepemilikan kendaraan bermotor roda dua mencapai 137,7 juta unit dan ada penambahan sekitar 6,3 juta unit pada tahun 2019.

Dengan banyaknya kendaraan bermotor roda dua yang ada di Indonesia tidak menutup kemungkinan juga akan terjadinya tindak kriminal pencurian kendaraan roda dua, pada tahun 2017 di salah satu wilayah di Indonesia Satuan Reserse Kriminal (Satreskrim) mengungkap kan telah terjadi tindak pidana pencurian kendaraan roda dua sebanyak 151 kejadian dan meningkat sebesar 45,7 persen atau sekitar 220 kasus pencurian kendaraan roda dua pada tahun 2018.

Untuk menambah kemanan sepeda motor dari pencurian maka dipadukan antara alarm sepeda motor dengan teknologi Internet of Things (IoT).

IoT merupakan sebuah konsep yang bertujuan untuk memperluas manfaat dari konektifitas internet yang tersambung secara terus menerus. Pada dasarnya IoT mengacu pada benda yang dapat diidentifikasikan secara unik sebagai representasi virtual dalam struktur berbasis internet.

Tujuan dari perpaduan alarm sepeda motor dengan teknologi IoT adalah agar dapat memberikan peringatan melalui aplikasi telegram kepada pemilik sepeda motor terhadap pencurian. Untuk menerapkan teknologi IoT maka diperlukan suatu alat yang dapat berkomunikasi dengan telegram yaitu 
dengan menggunakan NodeMcu Wemos LoLin V3 dan dilengkapi sensor lainnya seperti sensor tegangan, sensor getar dan juga relay.

\section{LANDASAN TEORI}

\subsection{Internet of Things (IoT)}

IoT merupakan sebuah konsep yang bertujuan untuk memperluas manfaat dari konektifitas internet yang tersambung secara terus menerus. Pada dasarnya IoT mengacu pada benda yang dapat diidentifikasikan secara unik sebagai representasi virtual dalam struktur berbasis internet.

Menurut Fawzi Behmann dan Kwok Wu: IoT adalah sebuah istilah yang dimaksudkan dalam penggunaan internet yang lebih besar, mengadopsi komputasi yang bersifat mobile dan konektifitas kemudian menggabungkanya kedalam kesehari-harian dalam kehidupan kita.

IoT berkaitan dengan DoT (Disruption of Things) sebagai pengantar perubahan penggunaan internet dari Internet of People menjadi Internet of M2M (Machine to Machine).

\subsection{Model Prototipe}

Menurut Ogedebe, dkk (2012) "prototyping merupakan metode pengembangan perangkat lunak, yang berupa model fisik kerja sistem dan berungsi sebagai versi awal dari sistem".

Ogedebe (2012), menyampaikan bahwa "Prototyping dimulai dngan pengumpulan kebutuhan, melibatkan pengembang dan pengguna sistem untuk menentukan tujuan, fungsi dan kebutuhan operasional sistem".

Terdapat empat tahap dalam menggunakan model prototipe, yaitu:

1. Analisa Kebutuhan, dilakunan guna mengetahui komponen apa saja yang diperlukan dalam membangun sistem yang sedang berjalan, seperti hardware, software, jaringan, serta user sebagai pengguna akhir.

2. Desain Sistem, merupakan kegiatan yang menghasilkan berupa spesifikasi dari sistem yang dibuat. Bagian dari desainnya dapat berupa desain interface, proses, data dengan tujuan menghasilkan spesifikasi sistem yang sesuai dengan kebutuhan.

3. Pengujian Sistem, Dengan melakukan tahap ini, diharapkan sebuah sistem dapat berjalan sesuai dengan tahap-tahap yang sebelumnya dilakukan. Pada tahap ini melibatkan developer ataupun developer dengan user yang akan terlibat.

4. Implementasi, pada tahap ini dapat diimplementasikan setelah pengguna menyetujui dari kerja sistem yang sudah diuji sebelumnya.

\subsection{Mikrokontroler}

Mikrokontroler (pengendali mikro) pada suatu rangkaian elektronik berfungsi sebagai pengendali yang mengatur jalannya proses kerja dari rangkaian elektronik. Di dalam sebuah IC mikrokontroler terdapat CPU, memori, timer, saluran komunikasi, serial dan paralel, port input/output, dan lainnya.

\subsection{NodeMcu}

NodeMcu merupakan sebuah opensource platform untuk IoT yang menggunakan bahasa pemrograman LUA untuk membantu dalam pembuatan prototipe yang berbasis teknologi IoT.

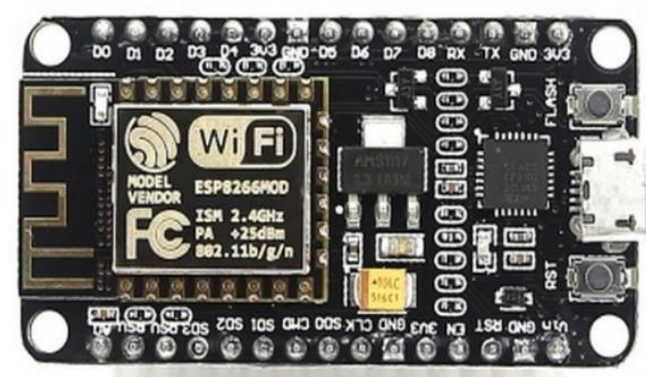

Gambar 1. Wemos LoLin V3 Esp8266

(Sumber: Nyebarilmu.com)

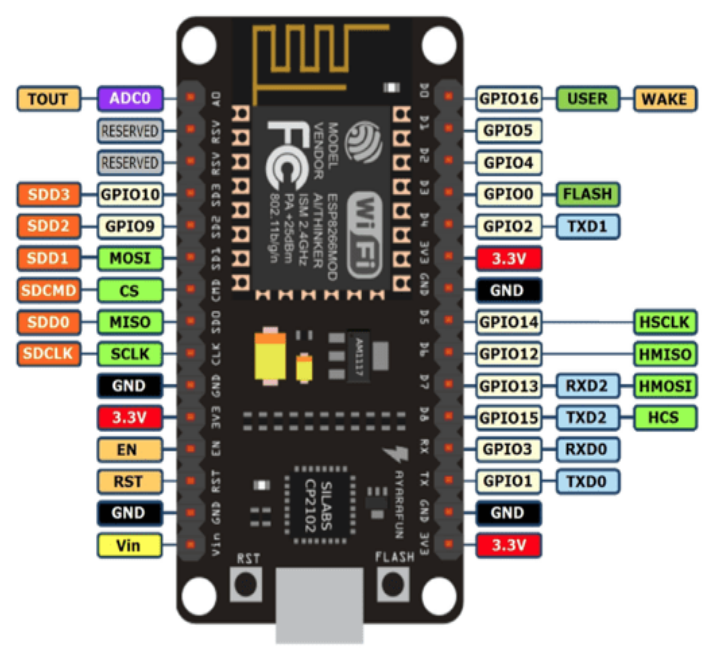

Gambar 2. Skema Wemos Lolin V3 (Sumber: Nyebarilmu.com) 
Wemos LoLin V3 merupakan NodeMcu dengan module WiFi Esp8266 dan Chip Programmer $\mathrm{CH} 340$ yang dapat di program dengan menggunakan software arduino IDE.

\subsection{Sensor Tegangan}

Sensor tegangan merupakan sebuah multisensor yang berfungsi untuk membaca nilai tegangan dari suatu rangkaian.

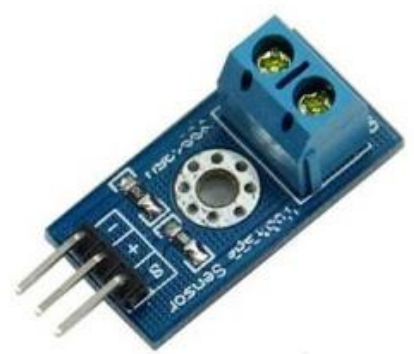

Gambar 3 Modul Sensor Tegangan

(Sumber: Blogspot.com)

Karena pin NodeMcu hanya bekerja pada tegangan maksimal $5 \mathrm{~V}$ maka jika range tegangan yang masuk ke NodeMcu $>5 \mathrm{~V}$ maka sensor tegangan ini yang berfungsi untuk mengatur tegangan yang masuk ke NodeMcu.

Tegangan yang masuk dan diterima oleh NodeMcu berupa nilai ADC (Analog Digital Converter). Untuk mengkonversi tegangan maka digunakan rumus seperti berikut:

keterangan:

Tegangan $=\mathrm{ADC} / 1023 * 5 \mathrm{~V}$

1023 adalah nilai ADC maksimal (10bit)

$5 \mathrm{~V}$ adalah tegangan maksimal yang dapat diterima oleh NodeMcu.

Jika tegangan input yang digunakan $>5 \mathrm{~V}$ maka perbandingannya adalah $\mathrm{Vi}: \mathrm{Vo}=6: 1$.

$$
\begin{array}{r}
V i=A D C / 1023 * 5 V \\
V 0=V i * 6
\end{array}
$$

\subsection{Sensor Getar}

Sensor getar merupakan sebuah sensor yang berfungsi untuk mendeteksi adanya suatu getaran pada suatu benda. Sensor ini sering di implementasikan untuk mengantisipasi adanya mara bahaya.

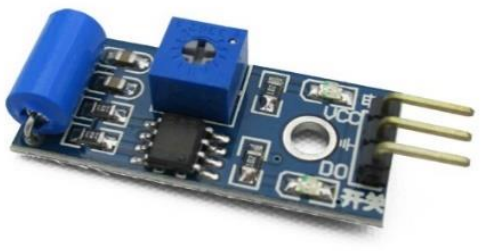

Gambar 4 Modul Sensor Getar (Sumber: BoArduino)
Sensor getar yang sering digunakan yaitu accelerometer, accelerometer merupakan sebuah alat yang berfungsi untuk mengukur percepatan berdasarkan fenomena pergerakan dari suatu benda yang dihubungkan dengan perubahan massa yang terjadi di dalam alat ukur tersebut.

\subsection{Relay}

Relay adalah saklar (switch) yang dioperasikan secara otomatis oleh tegangan listrik dan merupakan komponen electromechanical yang terdiri dari dua bagian utama yaitu electromagnet (coil) dan mekanikal (seperangkat kontak saklar). Relay menggunakan prinsip elektromagnetik untuk menggerakkan kontak saklar sehingga dengan arus listrik yang kecil (low power) dapat menghantarkan listrik yang bertegangan lebih tinggi.

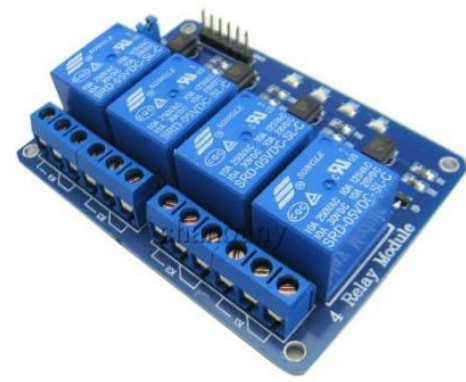

Gambar 5 Modul Relay

(Sumber: academia.edu)

Pada dasarnya relay terdiri dari 4 komponen dasar yaitu electromagnet, Armature, Saklar, Spring. Berikut adalah gambar struktur sederhana dari sebuah relay.

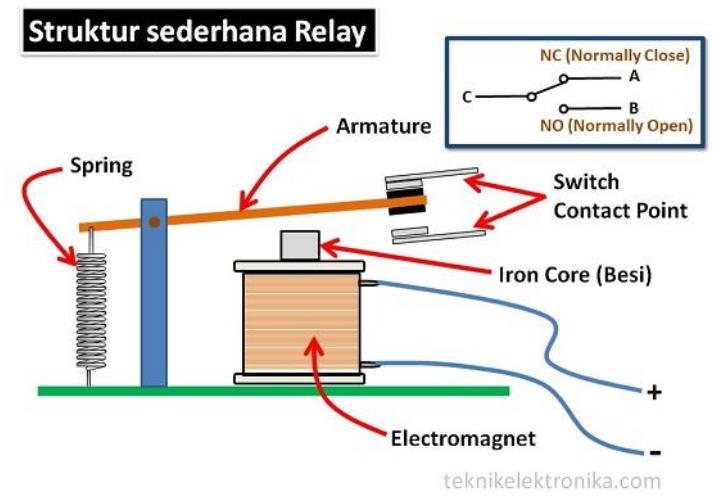

Gambar 6 Struktur Sederhana Relay (Sumber: teknikelektronika.com) 
Kontak poin (contact point) relay terdiri dari dua jenis, yaitu:

1. Normally Close, yaitu kondisi awal sebelum diaktifkan akan selalu berada di posisi close (tertutup).

2. Normally Open, yaitu kondisi awal sebelum diaktifkan akan selalu berada di posisi open (terbuka).

\subsection{Buzzer}

Buzzer adalah komponen elektronika yang dapat mengubah sinyal listrik menjadi getaran suara. Cara kerja dari komponen ini yaitu pada saat ada arus listrik yang mengalir pada komponen ini maka komponen ini akan mengubah arus listrik menjadi energi suara yang dapat didengar oleh manusia.

Buzzer memiliki dua jenis yaitu passive buzzer dan active buzzer. Passive Buzzer merupakan komponen buzzer yang tidak memiliki suara sendiri, dengan kata lain ketika komponen ini diberi arus listrik maka komponen ini tidak akan menghasilkan suara, contohnya seperti speaker aktif. Sedangkan active buzzer merupakan komponen buzzer yang memiliki suara sendiri atau ketika komponen ini diberi arus listrik maka komponen ini akan menghasilkan energi suaranya sendiri.

\subsection{Motor DC}

Motor DC adalah motor yang bergerak berputar 360 derajat, motor DC biasa juga disebut dengan dynamo dan biasa digunakan sebagai penggerak roda. Apabila kutub positif dan negatif sumber yang dipasang ditukar maka motor DC akan berputar berlawanan arah dari arah putar sebelumnya.

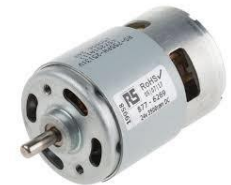

Gambar 7 Motor DC

(Sumber: Sinaupedia)

\section{PERANCANGAN DAN PEMBUATAN}

\subsection{Blok Diagram}

Blok Diagram adalah diagram dari sebuah sistem dimana bagian utama atau fungsi yang diwakili oleh blok dihubungkan dengan garis yang menunjukan hubungan dari blok. Blok diagram banyak digunakan dalam dunia rekayasa dalam desain hardware, software, dan elektronik.

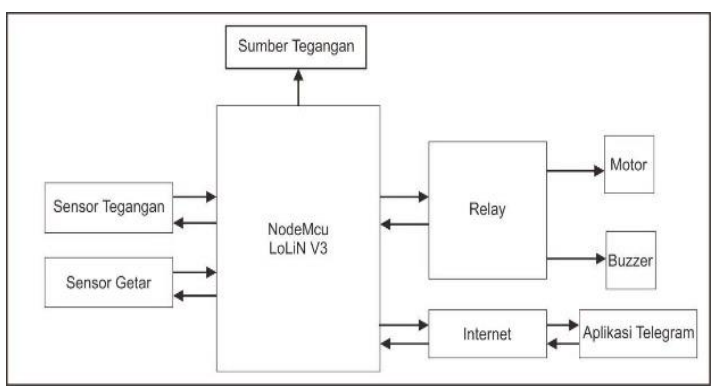

Gambar 8 Blok Diagram

Alarm kendaraan sepeda motor ini masih berupa prototipe. Dalam prototipenya alarm kendaraan sepeda motor ini didesain agar alarm motor dapat dikendalikan oleh penggunanya secara jarak jauh. Alarm motor dibuat agar apabila terjadi sesuatu terhadap kendaraan maka alarm motor dapat memberi report ke pengguna melalui smartphone dengan media aplikasi telegram dan juga pengguna memiliki kendali untuk memberi intruksi terhadap alarm motor untuk menyalakan dan mematikan motor.

\subsection{Perencanaan Catu Daya}

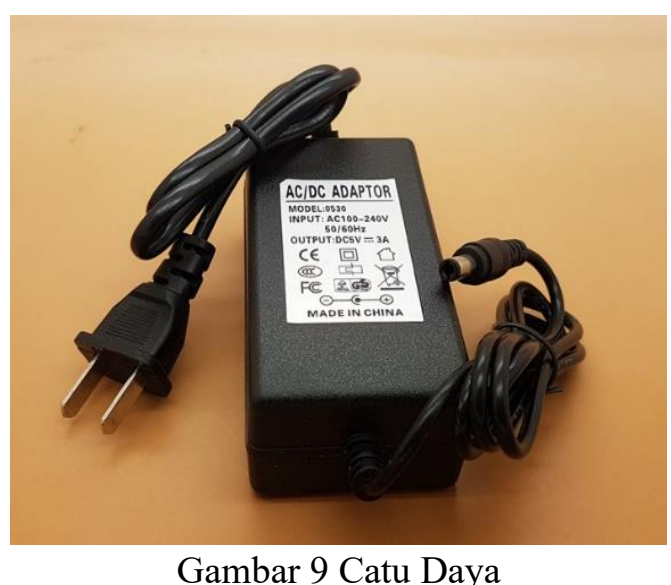

Catu daya yang digunakan pada penelitian ini menggunakan catu daya dengan input $100-$ $250 \mathrm{~V}, 50-60 \mathrm{~Hz}$ dan output 5V, $3.0 \mathrm{~A}$.

\subsection{Perencanaan Sensor}

\subsubsection{Sensor Tegangan}

Prinsip kerja sensor ini yaitu berdasarkan prinsip penekanan resistansi, sensor ini dapat membuat tegangan berkurang lima kali dari tegangan asli. Sensor ini digunakan untuk mengatur tegangan yang masuk. 


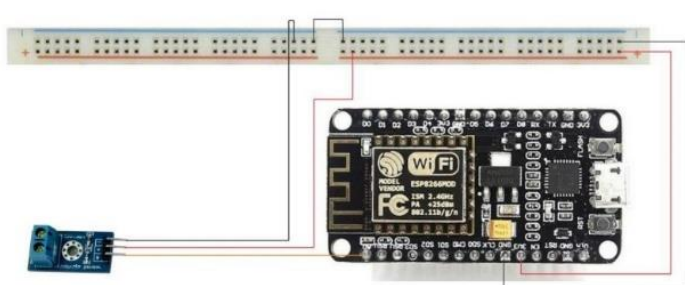

Gambar 10 Perancangan Sensor Tegangan

Berikut penerapan perencanaan pada sensor tegangan.

1. Pin tegangan $3.3 \mathrm{~V}$ pada wemos LoLiN V3 dipasang pada breadboard dengan no pin +50 .

2. Pin GND pada wemos LoLiN v3 dipasang pada breadboard dengan no Pin -50 .

3. Pin (s) pada sensor tegangan dipasang ke pin (A0) pada wemos LoLiN V3.

4. Pin $(+)$ pada sensor tegangan dipasang ke pin $(+27)$ pada breadboard

5. Pin (-) pada sensor tegangan dipasang ke pin (-23) pada breadboard.

\subsubsection{Sensor Getar}

Sensor ini digunakan untuk mendeteksi getaran pada saat kendaraan sedang dalam keadaan parkir.

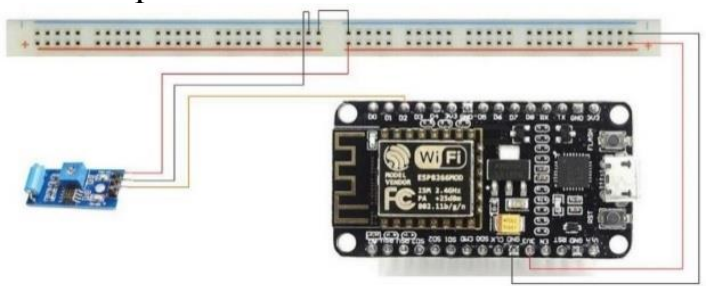

Gambar 11 Perancangan Sensor Getar

Berikut penerapan perencanaan pada sensor getar:

1. Pin VCC pada sensor getar dihubungkan ke pin (+26) pada breadboard.

2. Pin GND pada sensor getar dihubungkan ke pin (-24) pada breadboard.

3. Pin D0 pada sensor getar dihubungkan ke pin D1 pada wemos LoLiN V3.

\subsection{Perencanaan NodeMcu}

NodeMcu yang digunakan adalah NodeMcu LoLiN V3 dengan modul WiFi Esp8266 dan chip CH340. NodeMcu berfungsi sebagai pemberi intruksi kepada perangkat-perangkat yang lain, sedangkan NodeMcu akan diberi intruksi oleh pengguna melalui device smartphone atau Laptop menggunakan media Telegram.

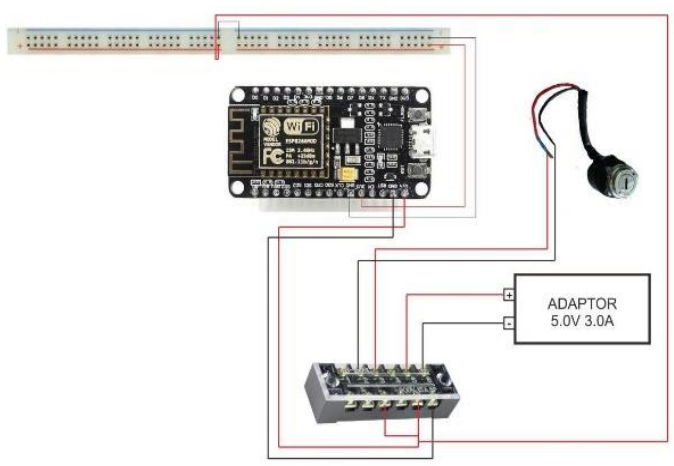

Gambar 12 Perancangan NodeMcu

Berikut penerapan perencanaan NodeMcu seperti di atas:

1. Kabel tegangan pada adaptor dipasangkan ke terminal no 5 .

2. Kabel ground pada adaptor dipasangkan ke terminal no 6 .

3. Kabel tegangan pada saklar kunci kontak motor dipasangkan ke terminal no 3.

4. Kabel ground pada saklar kunci kontak motor dipasangkan ke terminal no 2 .

5. Sambungkan kabel baru dipasangkan ke terminal no 3 dan 5 agar kontak memiliki tegangan yang di suplai oleh adaptor.

6. Sambungkan pin VIN pada NodeMcu ke terminal no 5.

7. Sambungkan pin GND pada NodeMcu ke terminal no 6 .

8. Sambungkan kabel dari terminal no 5 ke board $(+25)$ agar board $(+1$ sampai +25$)$ memiliki tegangan $5 \mathrm{v}$.

\subsection{Perencanaan Terminal}

Dalam penelitian ini tahap perencanaan terminal menggunakan media internet sebagai penghubung antara NodeMcu dengan smartphone, selain dengan media internet untuk menghubungkan antara NodeMcu dengan smartphone didukung juga dengan aplikasi bot telegram. Dengan memasukan token bot pada program arduino maka dengan dukungan internet NodeMcu dapat saling berkomunikasi dengan device pengguna melalui aplikasi Telegram.

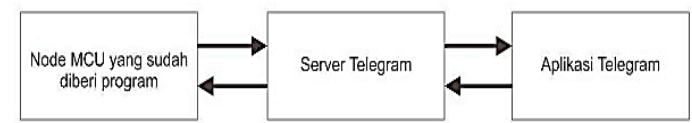

Gambar 13 Blok Diagram Terminal 


\subsection{Perencanaan Relay}

Relay yang digunakan adalah relay 4 channel 5V. Relay digunakan untuk menutup dan membuka arus listrik sesuai intruksi dari NodeMcu. Bila channel relay diberi arus listrik maka relay akan meneruskan arus listrik ke channel tertentu sesuai dengan intruksi dari NodeMcu yang sudah diprogram, lalu akan meneruskan arus listrik ke perangkat lain yang terhubung dengan relay tersebut.

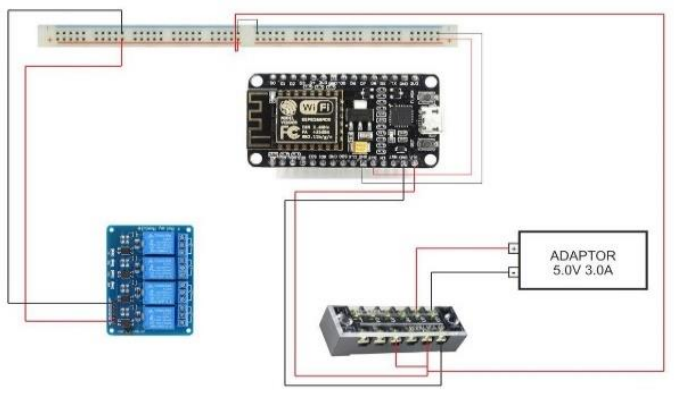

Gambar 14 Perancangan Relay

Berikut penerapan perencanaan relay:

1. Pin VCC pada Relay disambungkan ke bread board $(+10)$ yang memiliki tegangan $5 \mathrm{~V}$.

2. Pin GND pada relay disambungkan ke bread board (-10).

\subsection{Perencanaan Buzzer}

Active buzzer memiliki piezoelectric yang dapat mengubah energi listrik menjadi energi suara yang dapat didengar oleh manusia. Active buzzer akan menghasilkan suara apabila terdapat arus yang diteruskan oleh relay.

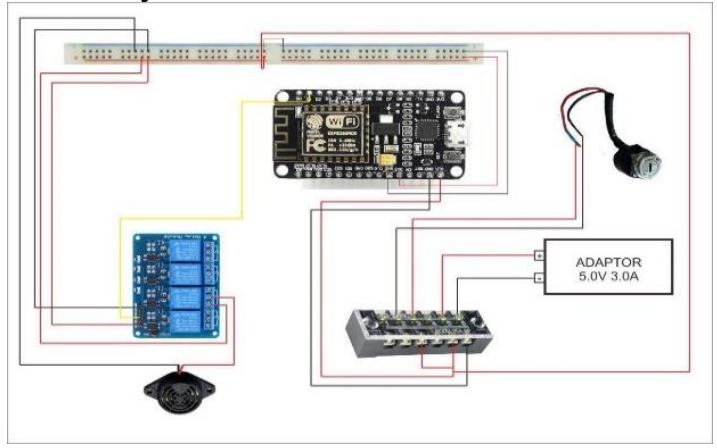

Gambar 15 Perencanaan Buzzer

1. Kabel arus pada active buzzer dihubungkan ke channel 3 relay.

2. Kabel ground pada active buzzer dihubungkan ke bread board (-8)

3. Sambungkan kabel untuk arus dari bread board (+9) ke channel 3 relay.
4. Sambugkan pin IN3 ke pin D1 pada NodeMcu agar relay dapat diberikan intruksi oleh NodeMcu yang sudah diprogram.

\subsection{Perencanaan Motor}

Dalam perencenaan motor pada penelitian ini menggunakan motor DC, motor DC dapat berputar 360 derajat apabila diberi arus listrik. Motor DC pada penelitian akan berputar apabila diberi arus listrik yang diteruskan oleh relay, relay akan memberikan arus listrik apabila menerima intruksi dari NodeMcu.

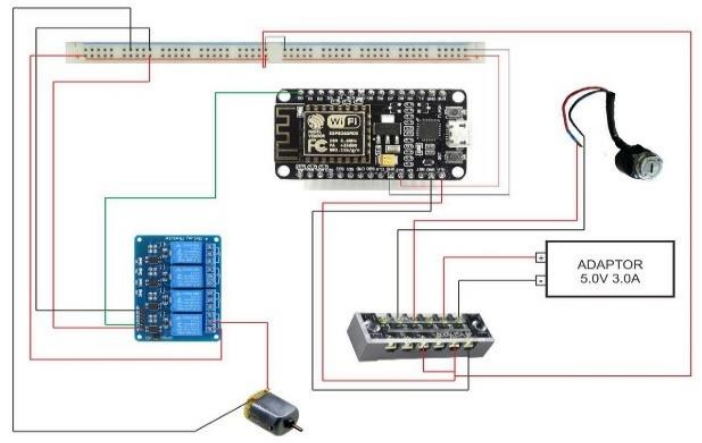

Gambar 16 Perancangan Motor

1. Sambungkan kabel arus pada motor dc ke channel 4 pada relay.

2. Sambungkan kabel ground pada motor dc ke bread board (-7).

3. Sambungkan kabel arus pada bread board $(+1)$ ke channel 4 pada relay.

4. Hubungkan pin IN4 pada relay ke pin D0 pada NodeMcu agar NodeMcu yang sudah diprogram dapat memberikan intruksi kepada relay.

\subsection{Perencanaan Pendukung Output}

Pendukung output dalam penelitian ini menggunakan aplikasi telegram dengan bot telegram yang sudah dibuat sebelumnya. Terdapat beberapa command yang dibuat untuk memberi intruksi dari telegram ke NodeMcu, diantaranya adalah sebagai berikut:

\section{1. /ALARM}

Intruksi ini akan membuat NodeMcu dalam keadaan alarm on, dimana saat alarm on maka:

a. Motor tidak dapat menyala.

b. Apabila terdeteksi adanya arus pada sensor tegangan maka buzzer akan menghasilkan suara dan memberi report pada pengguna melalui telegram. 


\section{2. /DISALARM}

Intruksi ini akan membuat NodeMcu dalam keadaan alarm off, dimana saat alarm off maka:

a. NodeMcu akan memberi report bahwa kondisi alarm dalam posisi off dan akan memberi pesan "/ON" untuk menghidupkan motor dan "/OFF" untuk mematikan motor.

b. Apabila diberi intruksi /ON maka motor akan hidup.

c. Apabila diberi intruksi /OFF maka motor akan mati.

\subsection{Flowchart Program}

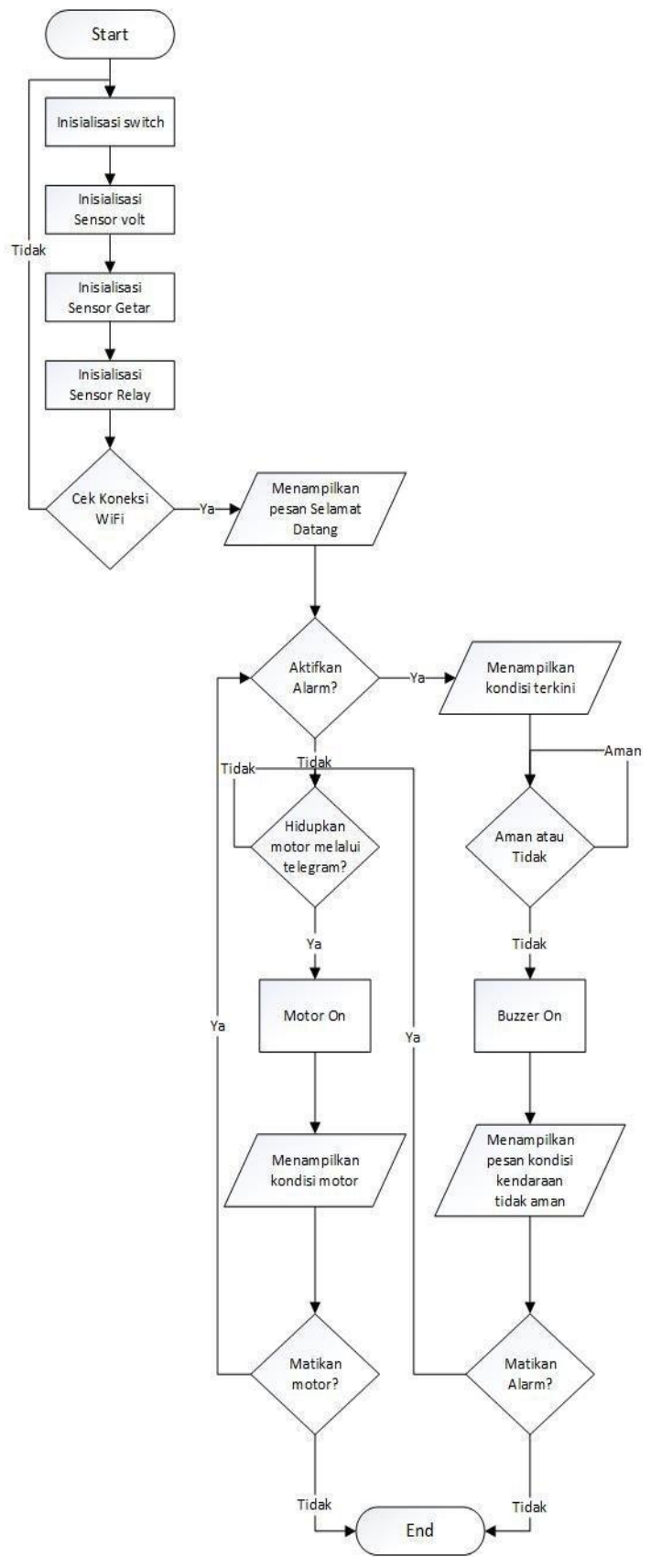

IV. PENGUJIAN DAN ANALISA

\subsection{Pengujian Catu Daya}

Tabel 1 Pengujian Catu Daya

\begin{tabular}{|c|c|c|}
\hline $\begin{array}{c}\text { OUTPUT } \\
\text { CATU } \\
\text { DAYA }\end{array}$ & $\begin{array}{c}\text { Input ke } \\
\text { NodeMcu }\end{array}$ & Keterangan \\
\hline $5.0 \mathrm{~V}, 2.0 \mathrm{~A}$ & $5.0 \mathrm{~V}, 2.0 \mathrm{~A}$ & $\begin{array}{c}\text { NodeMcu } \\
\text { menyala, } \\
\text { komponen } \\
\text { relay tidak } \\
\text { berjalan } \\
\text { dengan baik }\end{array}$ \\
\hline $5.0 \mathrm{~V}, 3.0 \mathrm{~A}$ & $5.0 \mathrm{~V}, 3.0 \mathrm{~A}$ & $\begin{array}{c}\text { NodeMcu } \\
\text { menyala dan } \\
\text { komponen- } \\
\text { komponen } \\
\text { lain berjalan } \\
\text { dengan baik }\end{array}$ \\
\hline
\end{tabular}

Dari table hasil pengujian tersebut dapat disimpulkan bahwa catu daya dengan $5.0 \mathrm{~V}$, 3.0A dapat digunakan agar alarm kendaraan sepeda motor yang dibuat dapat digunakan sesuai dengan yang di harapkan.

\subsection{Pengujian Sensor Tegangan}

Pengujian sensor voltase berjalan dengan baik, ditunjukan dengan membuat program menggunakan pengondisian. Dengan tegangan yang telah disesuaikan, apabila saklar dalam posisi "on" sensor voltase dapat membaca tegangan dan meneruskan arus listrik menuju relay sehingga dapat menyalakan active buzzer.

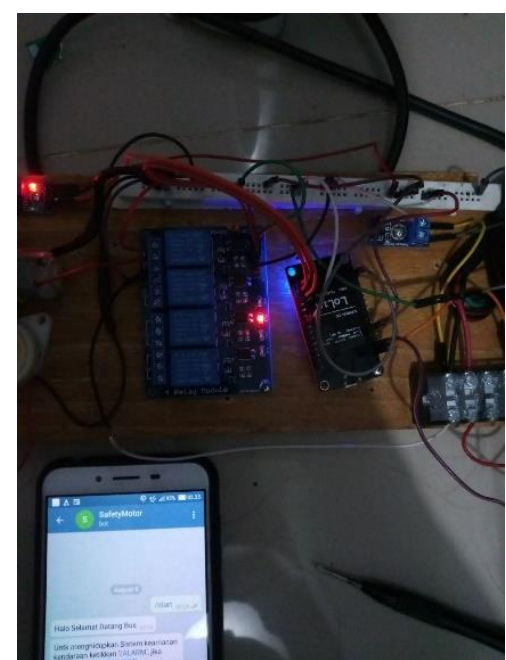

Gambar 17 Pengujian Sensor Tegangan 


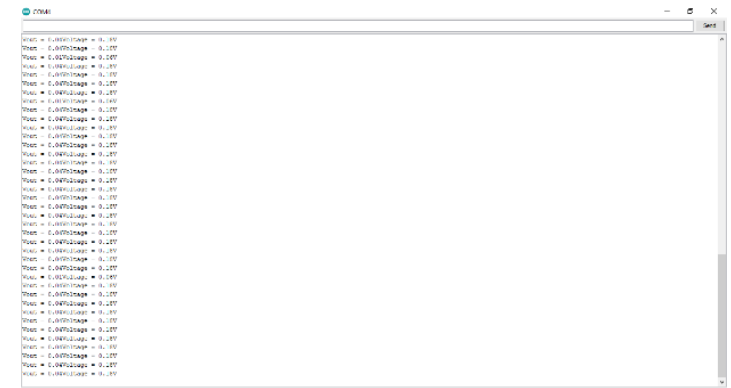

Gambar 18 Serial Monitor Hasil Sensor Tegangan

\subsection{Pengujian WiFi Esp8266}

WiFi Esp8266 diuji dengan mencoba disambungkan ke internet menggunakan hotspot WiFi dari sebuah smartphone.

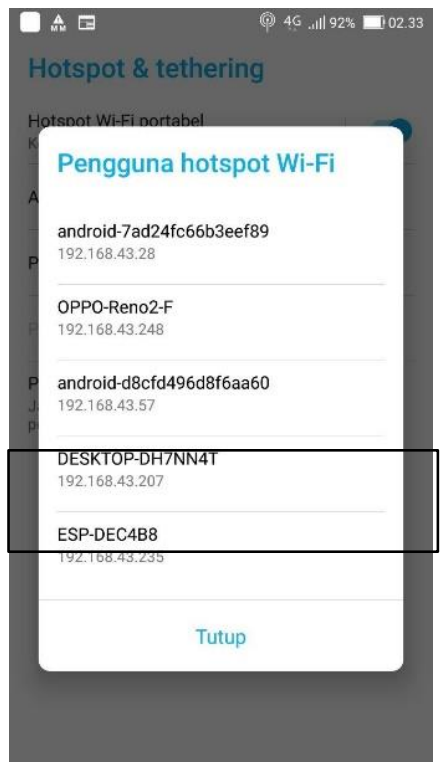

Gambar 19 Pengujian WiFi Esp8266

Dilihat dari gambar diatas bahwa WiFi Esp8266 berjalan dengan baik dan dapat terhubung ke internet.

\subsection{Pengujian Proses}

Pengujian proses dilakukan dari tahap awal catu daya hingga semua komponen berjalan dengan sesuai. Ketika WiFi Esp8266 sudah terhubung dengan internet baru dapat dilakukan uji proses. Hasil uji proses dapat dilihat dari gambar berikut.

Dilihat dari gambar hasil uji proses dengan mencoba mengkomunikasikan antara NodeMcu dan Telegram dapat disimpulkan bahwa proses berjalan dengan baik. Ketika NodeMcu diberi intruksi melalui telegram NodeMcu langsung memproses intruksi tersebut dan memberi respon dengan mengirimkan pesan ke Telegram.

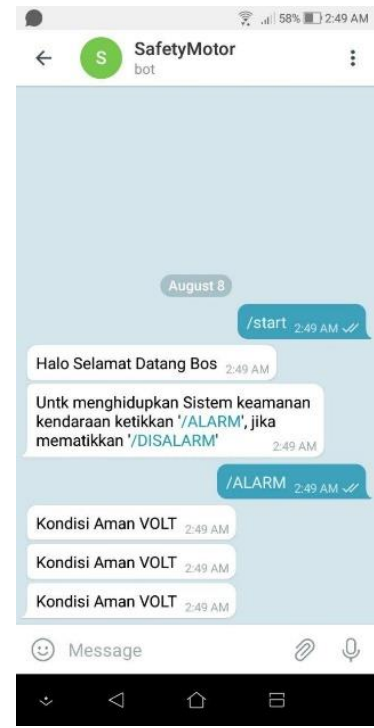

Gambar 20 Pengujian Proses

\subsection{Pengujian Output}

Pengujian dilakukan dari tahap telegram memberikan intruksi kepada NodeMcu untuk menyalakan relay yang terhubung dengan motor dan buzzer. Berikut gambar dari hasil pengujian output.

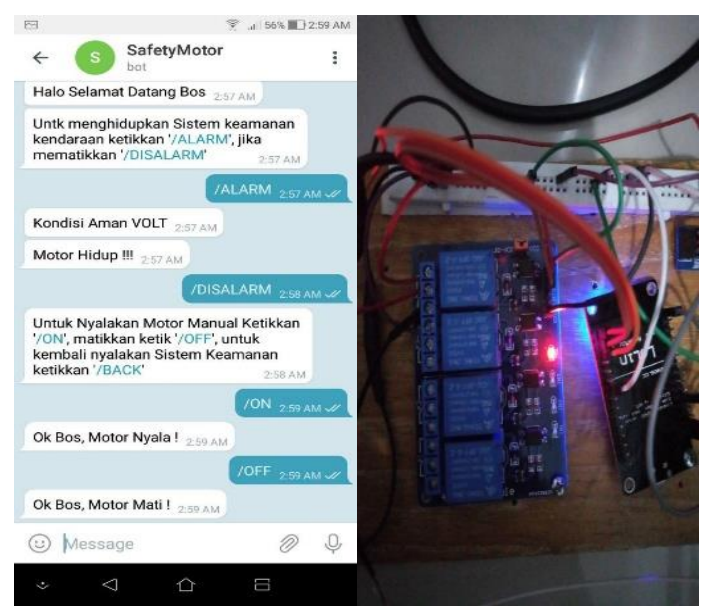

Gambar 21 Pengujian Output

Dilihat dari hasil pengujian dapat disimpulkan bahwa ketika NodeMcu diberi intruksi /Alarm maka kondisi alarm akan berada dalam posisi "on" dan jika dalam keadaan alarm "on" saklar dibuat menjadi posisi "on" maka sensor tegangan akan mendeteksi tegangan masuk dan meneruskan arus listrik menuju relay channel 3 yang tersambung dengan buzzer dan buzzer akan memberikan signal berupa suara serta NodeMcu akan memberikan respon dengan mengirimkan pesan ke Telegram.

Apabila NodeMcu diberi perintah /ON maka NodeMcu akan memberi tegangan 
kepada relay channel 4 yang tersambung dengan motor dan motor akan menghasilkan gerakan putaran lalu NodeMcu akan memberi respon dengan mengirimkan pesan melalui telegram.

\subsection{Analisa Hasil}

Setelah melewati beberapa prosedur pengujian untuk seluruh komponen perangkat keras maupun perangkat lunak dan didapatkan data-data yang dibutuhkan. Didapatkan hasil keseluruhan yang dapat berfungsi dengan cukup baik. Berikut data analisa dan hasil pengujian:

Tabel 2 Analisa Hasil

\begin{tabular}{|c|c|c|c|c|}
\hline $\begin{array}{l}\text { Pengu } \\
\text { jian }\end{array}$ & $\begin{array}{l}\text { Dihara } \\
\text { pkan }\end{array}$ & $\begin{array}{l}\text { Pengam } \\
\text { atan }\end{array}$ & Hasil & $\begin{array}{l}\text { Kesimp } \\
\text { ulan }\end{array}$ \\
\hline $\begin{array}{l}\text { Catu } \\
\text { Daya }\end{array}$ & $\begin{array}{l}\text { Terhub } \\
\text { ung } \\
\text { dengan } \\
\text { semua } \\
\text { kompo } \\
\text { nen }\end{array}$ & $\begin{array}{l}\text { Dapat } \\
\text { terhubu } \\
\text { ng } \\
\text { dengan } \\
\text { NodeM } \\
\text { cu }\end{array}$ & $\begin{array}{l}\text { Terhubu } \\
\text { ng }\end{array}$ & $\begin{array}{l}\text { Dapat } \\
\text { terhubu } \\
\text { ng } \\
\text { dengan } \\
\text { seluruh } \\
\text { kompon } \\
\text { en } \\
\text { perangk } \\
\text { at keras }\end{array}$ \\
\hline $\begin{array}{l}\text { Node } \\
\text { Mcu }\end{array}$ & $\begin{array}{l}\text { Dapat } \\
\text { Meneri } \\
\text { ma } \\
\text { intruksi } \\
\text { dan } \\
\text { membe } \\
\text { ri } \\
\text { respon } \\
\text { ke } \\
\text { telegra } \\
\text { m }\end{array}$ & $\begin{array}{l}\text { Dapat } \\
\text { meneri } \\
\text { ma } \\
\text { intruksi } \\
\text { dan } \\
\text { member } \\
\text { i respon } \\
\text { ke } \\
\text { telegra } \\
\text { m dan } \\
\text { kompon } \\
\text { en lain }\end{array}$ & $\begin{array}{l}\text { Terhubu } \\
\text { ng ke } \\
\text { telegram } \\
\text { dan } \\
\text { kompone } \\
\text { n lain }\end{array}$ & $\begin{array}{l}\text { NodeM } \\
\text { cu } \\
\text { dapat } \\
\text { meneri } \\
\text { ma } \\
\text { intruksi } \\
\text { dan } \\
\text { meneru } \\
\text { skan ke } \\
\text { kompon } \\
\text { en lain } \\
\text { serta } \\
\text { dapat } \\
\text { member } \\
\text { i respon } \\
\text { ke } \\
\text { telegra } \\
\text { m }\end{array}$ \\
\hline Relay & $\begin{array}{l}\text { Dapat } \\
\text { membu } \\
\text { ka } \\
\text { tutup } \\
\text { arus } \\
\text { listrik } \\
\text { sesuai } \\
\text { intruksi }\end{array}$ & $\begin{array}{l}\text { Relay } \\
\text { dapat } \\
\text { membu } \\
\text { ka tutup } \\
\text { arus } \\
\text { listrik } \\
\text { sesuai } \\
\text { intruk } \\
\text { yang } \\
\text { diberika } \\
\text { n } \\
\text { penggu } \\
\text { na ke } \\
\text { NodeM } \\
\text { cu }\end{array}$ & $\begin{array}{l}\text { Relay } \\
\text { terhubun } \\
\mathrm{g}\end{array}$ & $\begin{array}{l}\text { Relay } \\
\text { dapat } \\
\text { sesuai } \\
\text { menyal } \\
\text { akan } \\
\text { motor } \\
\text { dan } \\
\text { buzzer } \\
\text { sesuai } \\
\text { intruksi } \\
\text { yang } \\
\text { diberika } \\
\text { n }\end{array}$ \\
\hline $\begin{array}{l}\text { Active } \\
\text { Buzze } \\
r\end{array}$ & $\begin{array}{l}\text { Dapat } \\
\text { berbun } \\
\text { yi }\end{array}$ & $\begin{array}{l}\text { Berbun } \\
\text { yi } \\
\text { sesuai }\end{array}$ & $\begin{array}{l}\text { Menghas } \\
\text { ilkan } \\
\text { bunyi }\end{array}$ & $\begin{array}{l}\text { Active } \\
\text { Buzzer } \\
\text { dapat }\end{array}$ \\
\hline
\end{tabular}

\begin{tabular}{|c|c|c|c|c|}
\hline & $\begin{array}{l}\text { ketika } \\
\text { kondisi } \\
\text { alarm } \\
\text { on dan } \\
\text { kontak } \\
\text { pada } \\
\text { posisi } \\
\text { on }\end{array}$ & $\begin{array}{l}\text { dengan } \\
\text { yang } \\
\text { diharap } \\
\text { kan }\end{array}$ & & $\begin{array}{l}\text { berbuny } \\
\text { i ketika } \\
\text { kondisi } \\
\text { alarm } \\
\text { on lalu } \\
\text { terdapat } \\
\text { arus } \\
\text { listrik } \\
\text { yang } \\
\text { terdetek } \\
\text { si }\end{array}$ \\
\hline $\begin{array}{l}\text { Motor } \\
\text { DC }\end{array}$ & $\begin{array}{l}\text { Dapat } \\
\text { bergera } \\
\mathrm{k} \\
\text { ketika } \\
\text { ada } \\
\text { arus } \\
\text { masuk }\end{array}$ & $\begin{array}{l}\text { Motor } \\
\text { DC } \\
\text { dapat } \\
\text { bergera } \\
\text { k ketika } \\
\text { ada arus } \\
\text { masuk }\end{array}$ & $\begin{array}{l}\text { Menghas } \\
\text { ilkan } \\
\text { putaran } \\
360 \\
\text { derajat }\end{array}$ & $\begin{array}{l}\text { Motor } \\
\text { DC } \\
\text { bergera } \\
\text { k ketika } \\
\text { Relay } \\
\text { mendap } \\
\text { at arus } \\
\text { dari } \\
\text { NodeM } \\
\text { cu yang } \\
\text { sudah } \\
\text { diprogr } \\
\text { am }\end{array}$ \\
\hline
\end{tabular}

\section{KESIMPULAN DAN SARAN}

\subsection{Kesimpulan}

Berdasarkan penelitian yang sudah dilakukan, maka dapat disimpulkan bahwa:

1. Dapat menghasilkan prototipe alarm kendaraan sepeda motor dengan memanfaatkan teknologi Internet of Things.

2. Prototipe alarm kendaraan sepeda motor dapat terhubung ke internet dengan menggunakan modul WiFi Esp8266 pada NodeMcu sehingga alarm kendaraan sepeda motor dapat dikontrol oleh penggunanya secara jarak jauh.

3. Prototipe alarm kendaraan sepeda motor dapat mengirim respon melalui telegram sehingga pengguna dapat cepat tanggap apabila terdapat pesan respon di telegram.

\subsection{Saran}

Berdasarkan penelitian yang sudah dilakukan serta untuk meningkatkan kualitas penelitian, terdapat beberapa saran untuk penelitian selanjutnya sebagai berikut:

1. Prototipe dapat diimplementasikan dalam keadaan nyata dengan mengubah fitur tidak menggunakan Esp8266 namun dapat menggunakan Modul GSM sehingga alat dapat memiliki koneksi sendiri tanpa mengandalkan koneksi dari perangkat lain. 
2. Penambahan modul kamera yang dapat disimpan di bagian depan kendaraan sehingga apabila terjadi sesuatu maka alat akan mengirim gambar lalu mengirimnya ke pengguna sehingga pengguna dapat mengetahui apa yang terjadi.

\section{DAFTAR PUSTAKA}

[1] Ali, M. (2020). Kuliah Elektronika Daya Materi IX Rangkaian Dc Converter. Retrieved from Academia: https://www.academia.edu/38580811/K ULIAH_ELEKTRONIKA DAYA MA TERI_IX_RANGKAIAN_DC_CONVE RTER

[2] Andrianto, H., \& Darmawan, A. (Januari 2016). Arduino Belajar Cepat dan Pemrograman. Bandung: Informatika Bandung.

[3] Blythe, F. (2019). Pengertian IC dan Penjelasannya. Retrieved from Academia.edu:

https://www.academia.edu/38364409/Pe ngertian_IC_dan_penjelasannya.docx

[4] Ghamal. (2020, 04 03). Pengertian relay dan fungsinya. Retrieved from Academia:

https://www.academia.edu/22250403/Pe ngertian_Relay_dan_Fungsinya

[5] Hidayati, Sudarto, F., \& Ramdani, D. (2012). Sistem Keamanan Menggunakan Mikrokontroler AT89S52 Berbasis SMS Sebagai Cara Baru Mengatasi Pencurian Sepeda Motor. Eksplora Informatika, II, 71-72.

[6] Indra. (2019, Januari 17). Di 2018 Kasus Pencurian Motor Naik 45,7 Persen. Retrieved from Motor plus: https://www.motorplusonline.com/read/251605921/di-2018kasuspencurian-motor-naik-457-persendaerah-mana-ini-ya.

[7] Nugroho, A. (2011). Perancangan dan Implementasi Sistem Basis Data. Jakarta.

[8] Oroh, Joyner R; Kendekallo, Elia; Sompie, Sherwin R. U. A; Wuwung, Janny O. (2014). RANCANG BANGUN SISTEM KEAMANAN MOTOR DENGAN PENGENALAN SIDIK JARI. Jurnal Teknik Elektro dan Komputer, III, 1-2.

[9] Purnomo, D. (2017). Model Prototyping Pada Pengembangan Sistem Informasi.
Jurnal Informatika Merdeka Pasuruan, 55-59. Retrieved from https://media.neliti.com/media/publicati ons/264541-model-prototyping-padapengembangan-sist-1571738b.pdf.

[10] Saputro, T. T. (2017, April 19). Mengenal NodeMCU: Pertemuan Pertama. Retrieved from embeddednesia:

https://embeddednesia.com/v1/tutorialnodemcu-pertemuan-pertama/.

[11] Satzinger, Jackson, \& Burd. (2012). Sistems Analysis And Design In Changing.

[12] Soumerville, I. (2011). Software Engineering (Rekayasa Perangkat Lunak). Jakarta: Erlangga.

[13] Suryana, R. A. (2019). Pembangunan Sistem Keamanan Sepeda Motor Menggunakan GPS Tracking Dan Kunci Kontak Pintar Berbasis Mikrokontroler Arduino. UNIKOM Repository, 1-5.

[14] Viva. (2019). Jumlah Motor di Indonesia, Separuh Populasi Penduduknya. Retrieved from https://m.viva.co.id/amp/otomotif/motor /1129068jumlah-motor-di-indonesiaseparuh-populasi-penduduknya. 